DOI: $10.4274 /$ tpa.266

\title{
Analysis of pediatric forensic cases presented to emergency department
}

\author{
Ömer Faruk Demir1, Kemal Aydın1, Feruza Turan1, Aynur Yurtseven1, Bülent Erbil2, Betül Gülalp33 \\ ${ }^{1}$ Dışkapı Yıldııım Beyazıt Education and Research Hospital, Division of Emergency Medicine, Ankara, Turkey \\ 2Hacettepe University, Medical Faculty, Division of Emergency Medicine, Ankara, Turkey \\ 3Başkent University, Medical Faculty, Division of Emergency Medicine, Ankara, Turkey
}

\section{Summary}

Aim: Emergency services are departments where forensic cases are first admitted and their examination, diagnosis and treatments are performed. This study aimed to evaluate demographic and epidemiologic characteristics, reasons for presentation, admission time, and hospitalization and mortality rates in pediatric forensic cases presented to an emergency department.

Material and Method: Pediatric forensic cases below the age of 16 years who were admitted to an emergency department of a training research hospital within a 1-year period were evaluated retrospectively. The cases were evaluated in two groups as traumatic (traffic accidents, assault, occupational accident, sharp object injury, falls from high, gunshot injuries) and non-traumatic (suicide attempt, carbon monoxide intoxication) admissions.

Results: 1494 cases were included. The mean age was $8.8 \pm 4.37$ years, and $66 \%(n=986)$ of the cases were male. The majority of the cases $(29.5 \%)$ were in the 7-10-year age group. The most common reason for presentation was traffic accident $(76.4 \%)$, followed by fall from high (12.7\%) and assault (6.1\%). Cases were mostly admitted in the evenings and summer months. Of the cases, $9.2 \%$ was hospitalized and $1.9 \%$ required intensive care unit stay; mortality rate was $0.4 \%$.

Conclusions: Most forensic cases in childhood are preventable health problems. Identification of forensic case profiles of each region is needed to develop new strategies, take preventive measures and provide appropriate treatment approaches in emergency departments. (Turk Arch Ped 2013; 48: 235-240)

Key words: Child abuse, emergency medicine, pediatric forensic, traffic accident

\section{Introduction}

Emergency departments are the primary places where forencis cases are presented and where investigations, diagnosis and treatment are performed. Physicians should be aware of specific examination methods according to the charactersitics of forensic cases. This is much more important in pediatric cases where sufficient history can not be taken (1).

The main causes of pediatric injuries are reported to be motor vehicle accidents, falls, burns, intoxication, drowning, battery, firearm injuries, sharp object injuries, electric shock, asphyxia, torture, maltreatment, child abuse and suicide attempts. These types of cases are generally evaluated in the scope of forensic event $(2,3)$. In children and young adolescents, trauma is among the leading causes of mortality worldwide. Each year, approximately 150000 Americans die because of injuries. Non-fatal injuries constitute approximately $25 \%$ of all emergency department admissions (4).

In this study, it was aimed to determine the demographic and epidemiological characteristics, causes for presentation and hospitalization and mortality rates in pediatric forensic cases presented to the emergency department of an Education and Research Hospital and to compare them with the literature information. 


\section{Material and Method}

Patients below the age of 16 years who presented to the emergency department between January the 1st, 2008 and December the 31st, 2008 and considered as forensic case were included in the study. Hospital forensic recording information was evaluated retrospectively and patient information was recorded. The patients included in the study were examined in two groups as traumatic (traffic accidents, occupational accident, sharp object injury, falls, firearm injury and other) and non-traumatic (suicide attempt, carbonmonoxide intoxication) cases. The age, gender, reason for presentation and hospitalization and mortality rates of the patients were determined and statitical analysis was performed.

Statistical Package for Social Sciences (SPSS Inc., version 11.5; Chicago, IL) was used for statistical analysis. While the continuous variables were expressed as mean \pm Standard deviation, the categorical data were expressed as $\mathrm{n}(\%)$. The categorical data were analysed using Pearson Chi-square or Fisher Exact test, when appropriate. A p value of $<0.05$ was considered statistically significant.

\section{Results}

The mean age of 1494 pediatric patients evaluated in the study was $8.8 \pm 4.37$ years and $66 \%$ were male $(n=986)$. Most of the patients were in the 7-10-year age group (\%29.5). The distribution of the patients according to age groups is shown in Figure 1.

$98 \%$ of the cases $(n=1464)$ were traumatic and $2 \%$ $(n=30)$ were non-traumatic. In the traumatic group, the most common reason for presentation was traffic accidents $(76.4 \%)$. This was followed by falls $(12.7 \%)$ and battery $(6.1 \%)$. In the non-traumatic group, the most common reason for presentation was suicide attempt (1.4\%). In pediatric forensic cases, no clear assessement and recording under the name of child abuse was found. The reasons for presentation in forensic cases are summarized in Table 1.

When the distribution of the causes according to gender was evaluated, battery was found more frequently in boys $(p=0.003)$ and suicide attempt was found significantly more freequently in girls $(p<0.001)$. No difference was found between the genders for the other causes of presentation. Presentation because of battery was found more frequently in children at the age of 11 year and above. Presentation because of suicide attempt was found more frequently in children at the age 14 years and above. The rate of falls was higher in children at the age of 6 and below. Presentation because of traffic accident was found most commonly in the 7-10-year age group and least commonly in the age group of 14 years and above.

When the times of presentation were evaluated, it was observed that $57 \%$ of the patients $(n=860)$ presented

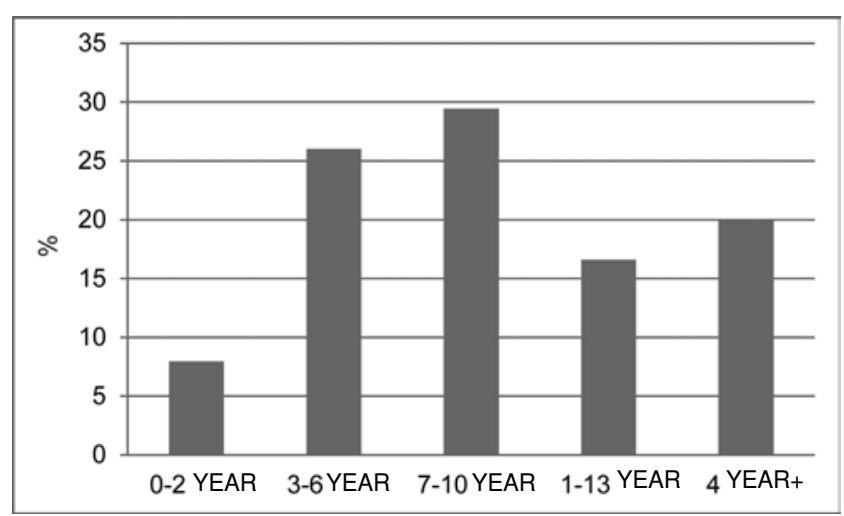

Şekil 1. Distribution of pediatric forensic cases by age groups

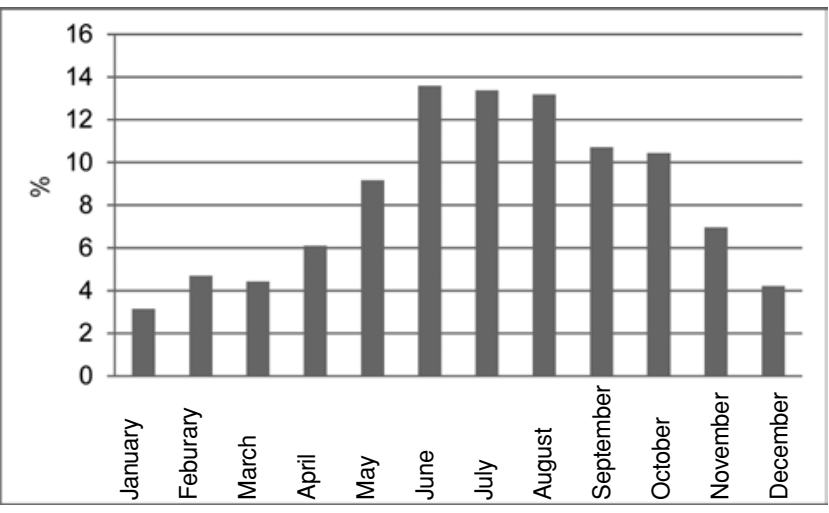

Şekil 2. Distribution of admissions of pediatric forensic cases by months

between 16:01 and 23:59. $8 \%$ of the patients $(n=117)$ presented between 00:00 and 08:00 and 35\% $(n=517)$ presented between 08:01 and 16:00.

When the times of presentation were evaluated by age groups, more than half of the patients in the 0-2 age group presented between 00:00 and 16:00, while more than half of the patients in the other age groups presented between 16:01 and 23:59 ( $p=0.007)$. Presentation between 16:01-23:59 was more frequent in boys, while presentation beween 00:00 and 16:00 was more frequent in girls $(p=0.026)$.

The distribution of forensic cases by months is shown in Figure 2. Presentations are observed to be more frequent in summer months. There was a significant difference between the age groups in terms of seasons of presentation $(p=0.001)$. The rate of presentation was more frequent in the age group of 11 years and above in the winter compared to the other age groups. Presentation was most frequent in the summer in the 3-6 year age group, while the rate of presentation in the autumn was generally similar in all age 
groups. No statistically significant difference was found in terms of gender in presentation seasons $(p=0,499)$.

It was found that $9,2 \%$ of the patients $(n=137)$ were treated by hospitalization in the ward and $1,9 \%$ were treated $(n=29)$ by hospitalization in the intensive care unit. Hospitalization rates by reasons of presentation are shown in Table 2. When hospitalization rates by reasons of presentation were evaluated, a statistically significant difference was found $(p<0,001)$. The rate of hospitalization was higher in patients who presented because of suicide attempt, traffic accident, firearm injuries and fall compared to the patients who presented because of battery $(p<0,05)$. The rate of hospitalization was higher in patients who presented because of suicide attempt compared to patients who presented because of traffic accidents and sharp object injuries $(p<0,001$ and $p=0,027)$. The rate of hospitalization was higher in patients who presented with sharp object injury and fall compared to patients who presented with traffic accident $(p<0,001$ and $p<0,001)$.

\begin{tabular}{|l|c|c|}
\hline \multicolumn{3}{|c|}{$\begin{array}{c}\text { Table 1. Reasons for presentation in forensic } \\
\text { cases }\end{array}$} \\
\hline Traumatic & n & $\%$ \\
\hline Traffic accidents & 1142 & 76.4 \\
\hline Falls & 189 & 12.7 \\
\hline Battery & 91 & 6.1 \\
\hline Sharp object injury & 14 & 0.9 \\
\hline Firearm injury & 7 & 0.5 \\
\hline Occupational accident & 6 & 0.4 \\
\hline Other & 15 & 1.0 \\
\hline Non-traumatic & $\mathbf{n}$ & $\%$ \\
\hline Suicide attempt & 21 & 1.4 \\
\hline CO intoxication & 9 & 0.6 \\
\hline
\end{tabular}

The rate of hospitalization was higher in patients who presented because of firearm injury compared to patients who presented because of $\mathrm{CO}$ intoxication, sharp object injury and fall $(p<0,019, p=0,006$ and $p=0,025)$.

No statistically significant difference was found between age and gender groups in terms of hospitalization rates (respectively $\mathrm{p}=0,425, \mathrm{p}=0,305$ ).

The rates of treatment in the intensive care unit in the groups are shown in Table 2. A statistically significant difference was found between the groups in terms of hospitalization in the intensive care unit (ICU) by reasons of presentation $(p<0,001)$. When comparison tests were done between the groups, it was observed that the rate of hospitalization in the intensive care unit was higher in patients who presented with suicide attempt and firearm injury compared to patients who presented with battery $(p<0.05)$. The rate of hospitalization in the intensive care unit was higher in patients who presented because of suicide attempt compared to patients who presented because of traffic accidents, sharp object injury and falls $(p<0.001$, $p=0.027$ and $p<0.001$ ). The rate of hospitalization in the intensive care unit was higher in patients who presented because of firearm injury compared to patients who presented because of traffic accidents $(p=0.005)$. The rate of hospitalization in the intensive care unit was higher in patients who presented because of firearm injury compared to patients who presented because of falls $(p=0.021)$. No statistically significant difference was found between the age and gender groups in terms of hospitalization rates in the ICU $(p=0.142, p=0.101)$.

$0.4 \%$ of the patients $(n=6)$ were lost. The mortality rates by reasons of presentation are shown in Table 2. Five of the cases who were lost were cases of traffic accidents and one was a case of fall. Four of the patients who were lost were male and two were female. Two of the patients

Table 2. Rates of hospitalization in the ward and in the intensive care unit and mortality rates in pediatric forensic cases

\begin{tabular}{|l|c|c|c|c|}
\hline Causes & $\mathbf{n}$ & $\begin{array}{c}\text { The rate of hospitalization } \\
\text { in the ward (\%) }\end{array}$ & $\begin{array}{c}\text { The rate of } \\
\text { hospitalization } \\
\text { in the ICU } \\
(\%)\end{array}$ & $\begin{array}{c}\text { Mortality rate } \\
\text { (\%) }\end{array}$ \\
\hline Traffic accident & 1142 & 7.8 & 1.2 & 0.4 \\
\hline Falls & 189 & 17.5 & 2.6 & 0.5 \\
\hline Battery & 91 & 1.1 & 0 & 0 \\
\hline Suicide attempt & 21 & 33.3 & 33.3 & 0 \\
\hline Sharp object injury & 14 & 0 & 0 & 0 \\
\hline CO intoxication & 9 & 0 & 0 & 0 \\
\hline Firearm injury & 7 & 57.1 & 28.6 & 0 \\
\hline Occupational accident & 6 & 16.7 & 0 & 0 \\
\hline Other & 15 & 13.3 & 6.7 & 0 \\
\hline
\end{tabular}


who were lost were in the 0-2 year age group, two were in the 3-6 year age group, one was in the 7-10 year age group and one was in the 11-13 year age group. No statistically significant difference was found between the groups of reason of presentation and the gender and age groups $(p=0.994 ; p=1.000$ and $p=0.230)$.

\section{Discussion}

In pediatric forensic cases, it may not be possible to take history sufficiently. Therefore, healthcare providers have a challenging task as to perform a detailed examination of the pediatric patients who present to the emergency department because of trauma and to make an evaluation of the forensic aspect of the event, if present. Especially in cases where history is not sufficient, physical examination findings, laboratory findings and imaging findings should be evaluated and the reasons of the event should be clarified using molecular examination methods including DNA analysis, if necessary (5-7). In such cases, knowing the attitude of each region in forensic cases will be directive in early diagnostic and therapeutical approach. We analyzed pediatric forensic cases admitted to the emergency department of our hospital in a period of one year to investigate the forensic case profile of our own region.

The mean age in the pediatric forensic cases admitted in our emergency department in our study was $8.8 \pm 4.37$ years. Most patients were in the 7-10 year age group and $66 \%$ were male. In traumatic forensic cases, the most common reason of presentation was traffic accidents $(76.4 \%)$. This was followed by falls $(12.7 \%)$ and battery $(6,1 \%)$. It was found that admissions were more common in the summer. Sever et al. (3) evaluated 486 pediatric forensic cases ( $\leq 17$ years) admitted in the emergency department of a tertiary care hospital in the study they performed. The mean age of the patients was $8.91 \pm 5.08$ years and most patients $(66.3 \%)$ were male. The number of cases was found to be higher in the 5-9 year age group ecompared to the other age groups. Summer was reported as the season when admissions were observed most frequently. The most common reason of presentation was accidental ingestion of drugs among non-traumatic cases, while the most common reason was traffic accident $(32.5 \%)$ among traumatic cases and this was followed by falls $(16.9 \%)$ and sharp object injuries (6.8\%). The reason that the rate of traumas and especially traffic accidents was high in our study was the fact that our hospital is considered as the pediatric trauma center in the province in which our hospital is found.

According to the Centers for Disease Control and Prevention (CDC) data approximately $2 / 3$ of all deaths in children and young adolescents between the ages of 5 and 19 years are due to injuries including motor vehicle accidents, unintentional injuries, murder and suicide attempt
(8). It is estimated that $90 \%$ of the unintentional injuries can be prevented as a result of simple precautions with a very disciplined approach in areas of education, engineering and sanction (4). Fatal traffic accidents in three metropoles in Hungary between the ages of 0 and 19 years were examined, age matching for mortality rate was done in the study period and was found to be 2.22-2.87 for each 100 000 people. The patients who had an accident were mostly in the $15-19$ age group (63\%) and male patients were found with a higher rate in each age group (9). When the data about 72 deaths due to external reasons in children below the age of 4 in Sweden between the years of 1977 and 2004 were evaluated, 15 (21\%) were found to be exposed to motor vehicle crush and $14(19 \%)$ were found to be passengers in motor vehicle accidents. In 12 children (17\%) the reason was intentional assault (10). In the analysis of all injuries and deaths between the ages of 0 and 17 years performed between 2000 and 2006 in San Diego County, California, it was found that 884 medicolegal examinations were done and mortality was due to external cause in 480 of these cases. Most of the patients were male (68.3\%) and the most common reason of mortality was traffic accidents. This was followed by asphyxia (22.7\%) and penetrating trauma (17.7\%). $40,9 \%$ of the deaths occured in the scene of accident, $35.5 \%$ occured during transportation and $28 \%$ occured at home (11).

In our study, falls were in the second order among the reasons of presentation with a rate of $12.7 \%$. Töro et al. (12) examined accidental falls, cases of jumping with the intention of suicide and falls with unknown reason in children and young adolescents (0-24 years of age) in Hungary. During the study, it was reported that $1.7 \%$ of all deaths in young adolescents were due to falls or jumping. It was reported that the rate of suicidal jumping had a tendency to increase among all causes of death (from $0.58 \%$ to $1.8 \%$ ). In our study, the highest mortality rate was found in cases of falls.

It is difficult to estimate the frequency of child abuse in the community. Deaths due to child abuse are observed mainly in relation with head trauma and severe neurological sequelae may be observed in survivors. Therefore, early diagnosis is important in these children (13). The prevalence of child abuse is estimated to be at least $1 \%$ in USA (14). The signs and symptoms of child abuse range from neglect/ignorance to sexual abuse or non-accidental head trauma including battered baby syndrome (BBS) (13). When the recordings of autopsies performed in the Forensic Medicine Institute in Belgrade were examined, it was found that there were 46 victims of murder in a 15 year period between the ages of 0 and 14 years (24 girsl and 22 boys). The most common cause of mortality was found to be blunt head trauma (15). Since children have 
different anatomical structures compared to adults, severe injuries with different biomechanical actions occur in cases of BBS (16). Severe internal injuries may occur in infants without any external finding (17). In many forensic cases including battery, suicide attempt, occupational accident and falls, child abuse should be considered and evidence should be searched. Although a clear forensic record about child abuse could not be found in pediatric forensic cases admitted to the emergency department in our study, a rate of battery of $6.1 \%$ suggests that the rate of cases of battered child or child abuse is high.

Maltreatment of children, sexual assault and/or abuse constitute an important social problem. Despite the importance and extensiveness of the issue, the number of studies reported is limited. $12 \%$ of adolescent girls are estimated to be victims of sexual abuse or assault (14). According to the recordings of 70 police centers in South Africa, sexual assault was determined in $7.4 \%$ of 596 children who were found to be the victim of assault (7). When 44 people below the age of 17 years exposed to sexual assault who were determined as forensic cases in a 3 month period in Rio de Janeiro (18) were examined, $84 \%$ were found to be in the age group of $0-14$ years during which self-defense capacity is lower. In a report in which 1054 pediatric forensic cases with a suspicion of sexual abuse were evaluated, $40.2 \%$ were found to be intrafamilial and these patients were reported to be affected more intensely compared to extra-familial cases (19). The reason that no sexual assault was reported in our study might have arised from the fact that such type of crimes are hidden because of emotions including shame and fear as a result of the sociocultural structure of the community.

Suicide is the third leading cause of mortality in adolescents between the ages of 15 and 24 years in USA and approximately 2 million adolescents attemp suicide each year (20). It is reported that female adolescents attempt suicide with a higher rate, but the rate of occurence of suicide is higher in male adolescents (20). It is recommended that children who carry a risk should be determined and controlled with a special approach to prevent the increase in cases of suicide. Presence of previous suicide attempt is the most important risk factor and the other risk factors include being older than 16 years of age, female gender, mood disorder, substance abuse, insufficient social support and access to firearms or fatal vehicles $(20,21)$. It was found that $24.4 \%$ of all medicolegal autopsies performed between 1997 and 2005 in the southern region of Turkey belonged to children and adolescents (0-18 years of age). It was found that $13.4 \%$ of the deaths below the age of 18 years occured due to suicide. It was reported girls constituted most cases of suicide $(62.9 \%)$ and the mean age was reported to be 16,1 years (22). In our study, the rate of presentation because of suicide attempt among pediatric forensic cases was found to be $1.4 \%$. Although the rate of suicide attempt was significantly higher in girls, there was no mortality.

It has been reported that healthcare workers do not have sufficient information about basic legal issues related with children and especially physicians who work in emergency departments need education on forensic medicine $(23,24)$. In addition, it has been reported that detailed investigations directed to find the real cause are not performed in children with fracture who present to emergency departments with trauma. It is recommended that a checklist be used in such cases for detailed interrogation (25). It has been reported that autopsy and postmortem examination should be performed to find the actual cause in cases of prenatal and neonatal death (26). Determination of the causes will provide appropriate precautions to be taken.

The majority of traumatic and non-traumatic pediatric cases considered as forensic cases are preventable health problems. Establishment of forensic case attitude of each region is important in terms of rapid and accurate approach in these cases. More epidemiological investigations are needed to take preventive measures and develop strategies in forensic cases.

\section{Conflict of interest: None declared.}

\section{References}

1. De Leeuw $M$, Jacobs W. Forensic emergency medicine: old wine in new barrels. Eur J Emerg Med 2010; 17: 186-191.

2. Mace SE, Gerardi MJ, Dietrich AM, Knazik SR, Mulligan-Smith $D$, Sweeney RL, Warden CR. Injury prevention and control in children. Ann Emerg Med 2001; 38: 405-414.

3. Sever M, Saz EU, Koşargelir M. An evaluation of the pediatric medico-legal admissions to a tertiary hospital emergency department. Ulus Travma Acil Cerrahi Derg 2010; 16: 260-267.

4. Feury KJ. Injury prevention. Where are the resources? Orthop Nurs 2003; 22: 124-130.

5. Offiah A, van Rijn RR, Perez-Rossello JM, Kleinman PK. Skeletal imaging of child abuse (non-accidental injury). Pediatr Radiol 2009; 39: 461-470.

6. Fernández-Rodríguez $\mathrm{A}$, Ballesteros $\mathrm{S}$, de Ory $\mathrm{F}$, Echevarría JE, Alvarez-Lafuente R, Vallejo G, Gómez J. Virological analysis in the diagnosis of sudden children death: a medico-legal approach. Forensic Sci Int 2006; 161: 8-14.

7. Jewkes R, Christofides N, Vetten L, Jina R, Sigsworth R, Loots L. Medico-legal findings, legal case progression, and outcomes in South African rape cases: retrospective review. PLoS Med 2009; 6: e1000164.

8. Centers for Disease Control and Prevention. School health guidelines to prevent unintentional injuries and violence. MMWR Recomm Rep 2001; 50: 1-73.

9. Töro K, Szilvia F, György D, Pauliukevicius A, Caplinskiene M, Raudys R, Lepik D, Tuusov J, Vali M. Fatal traffic injuries among children and adolescents in three cities (capital budapest, vilnius, and tallinn). J Forensic Sci 2011; 56: 617-620.

10. Björnstig U, Björnstig J, Ahlm K, Sjögren H, Eriksson A. Violent deaths in small children in northern Sweden. Int $\mathrm{J}$ Circumpolar Health 2006; 65: 28-34. 
11. Fraga AM, Fraga GP, Stanley C, Costantini TW, Coimbra R. Children at danger: injury fatalities among children in San Diego County. Eur J Epidemiol 2010; 25: 211-217.

12. Töro K, Szlávik N, Mészáros A, Dunay G, Soós M, Keller E. Jumping and falling death in children, adolescents, and young adults. J Clin Forensic Med 2006; 13: 129-134.

13. Adamsbaum C, Méjean N, Merzoug V, Rey-Salmon C. How to explore and report children with suspected non-accidental trauma. Pediatr Radiol 2010; 40: 932-938.

14. Santucci KA, Hsiao AL. Advances in clinical forensic medicine. Curr Opin Pediatr 2003; 15: 304-308.

15. Baralic I, Savic S, Alempijevic DM, Jecmenica DS, SbutegaMilosevic G, Obradovic M. Child homicide on the territory of Belgrade. Child Abuse Negl 2010; 34: 935-942.

16. Bandak FA. Shaken baby syndrome: a biomechanics analysis of injury mechanisms. Forensic Sci Int 2005; 151: 71-79.

17. Byard RW. Forensic aspects related to pediatric pathologyMedicolegal aspects of pediatric head injuries. Keio J Med 2006; 55: 149-152.

18. de Oliveira Aded NL, de Oliveira SF, da Silva Dalcin BL, de Moraes TM, Cavalcanti MT. Children and adolescents victimized by sexual abuse in the city of Rio de Janeiro: an appraisal of cases. J Forensic Leg Med 2007; 14: 216-220.
19. Magalhães T, Taveira F, Jardim P, Santos L, Matos E, Santos A. Sexual abuse of children. A comparative study of intra and extrafamilial cases. J Forensic Leg Med 2009; 16: 455-459.

20. Kennedy SP, Baraff LJ, Suddath RL, Asarnow JR. Emergency department management of suicidal adolescents. Ann Emerg Med 2004; 43: 452-460.

21. Wintersteen MB, Diamond GS, Fein JA. Screening for suicide risk in the pediatric emergency and acute care setting. Curr Opin Pediatr 2007; 19: 398-404.

22. Arslan M, Akçan R, Hilal A, Batuk H, Cekin N. Suicide among children and adolescents: data from Cukurova, Turkey. Child Psychiatry Hum Dev 2007; 38: 271-277.

23. Ashtekar CS, Hande A, Stallard E, Tuthill D. How much do junior staff know about common legal situations in paediatrics? Child Care Health Dev 2007; 33: 631-634.

24. Wiler JL, Bailey H, Madsen TE. The need for emergency medicine resident training in forensic medicine. Ann Emerg Med 2007; 50: 733-738.

25. Oral R, Blum KL, Johnson C. Fractures in young children: are physicians in the emergency department and orthopedic clinics adequately screening for possible abuse? Pediatr Emerg Care 2003; 19: 148-153.

26. Ozkara E, Canturk G, Canturk N, Ozata AB, Yavuz MF. Evaluation of forensic perinatal and neonatal autopsies in Istanbul. Indian $\mathrm{J}$ Pediatr 2009; 76: 167-170. 